\title{
Une espèce inédite de Rhachomyces (Ascomycètes, Laboulbeniales) parasite du Carabique troglobie, Speagonum mirabile Moore de la Nouvelle-Guinée \\ (Resultats Zoologiques de l'expedition spéléologique britannique en Papouasie-Nouvelle Guinée, 1975, 3)
}

par

\author{
Walter ROSSI*
}

\section{SUMMARY}

An new species of Rhachomyces (Ascomy cetes, Laboulbeniales) parasitic on the troglobite Carabid beetle Speagonum mirabile Moore, from New-Guinea (Zoological Results of the British Speleological Expedition to Papua-New Guinea, 1975, 3)

Rhachomyces beronii n. sp., parasitic on Speagonum mirabile Moore (Coleoptera, Carabidae, Anchomenini) from New Guinea, is described. The new species resembles Rhachomy'ces tenuis Thaxt. in general habit, but it differs from the latter in having a smaller receptacle, a larger and less pigmented perithecium, a different structure of the appendages and in the multiplication of appendiculate cells.

\section{Rhachomyces beronii species nova** (Fig. 1-2)}

Basalis et subbasalis cellulae oblongae; subbasalis ac cellulae continuae atrae. Praecipuus axis 20-30 quasi quadratis cellulis, atris in media parte ac clarioribus, interdum quasi hyalinis, prope septa, constat. Stigmata oblonga, conspicua. E cellulis superioribus praecipui ax is oriuntur breves secundarii axes ex oblongis cellulis compositi, quae obliquis septis separantur et singula antheridia aut singulas appendices ferunt. Appendices flexuosae, e 4-5 cellulis compositae, fuscis ac pellucidis, duplo vel triplo longioribus quam latioribus ac nigris crassisque septis separtis, preater ex tremam valde oblongam et ad apicem hyalinam.

\section{* Via P. Trogo 28, 00136 Roma. Italic}

**Au point de vue nomenclature, botanistes et zoologistes ont adopté des règles différentes:

a) pour former un nom du groupe-espèce d'après un patronyme moderne, les zoologistes ajoutent à la totalité du patronyme la désinence -i (ce qui est assez normal étant donné que c'est la désinence du génitif singulier) alors que les botanistes ajoutent la désinence -ii aux noms qui se terminent par une consonne.

b) Pour les zoologistes la description d'un nouveau taxon peut-être écrite en allemand, ou en anglais, ou en français, ou en italien, ou en latin, alors que les botanistes n'acceptent qu'une rédaction en latin. 


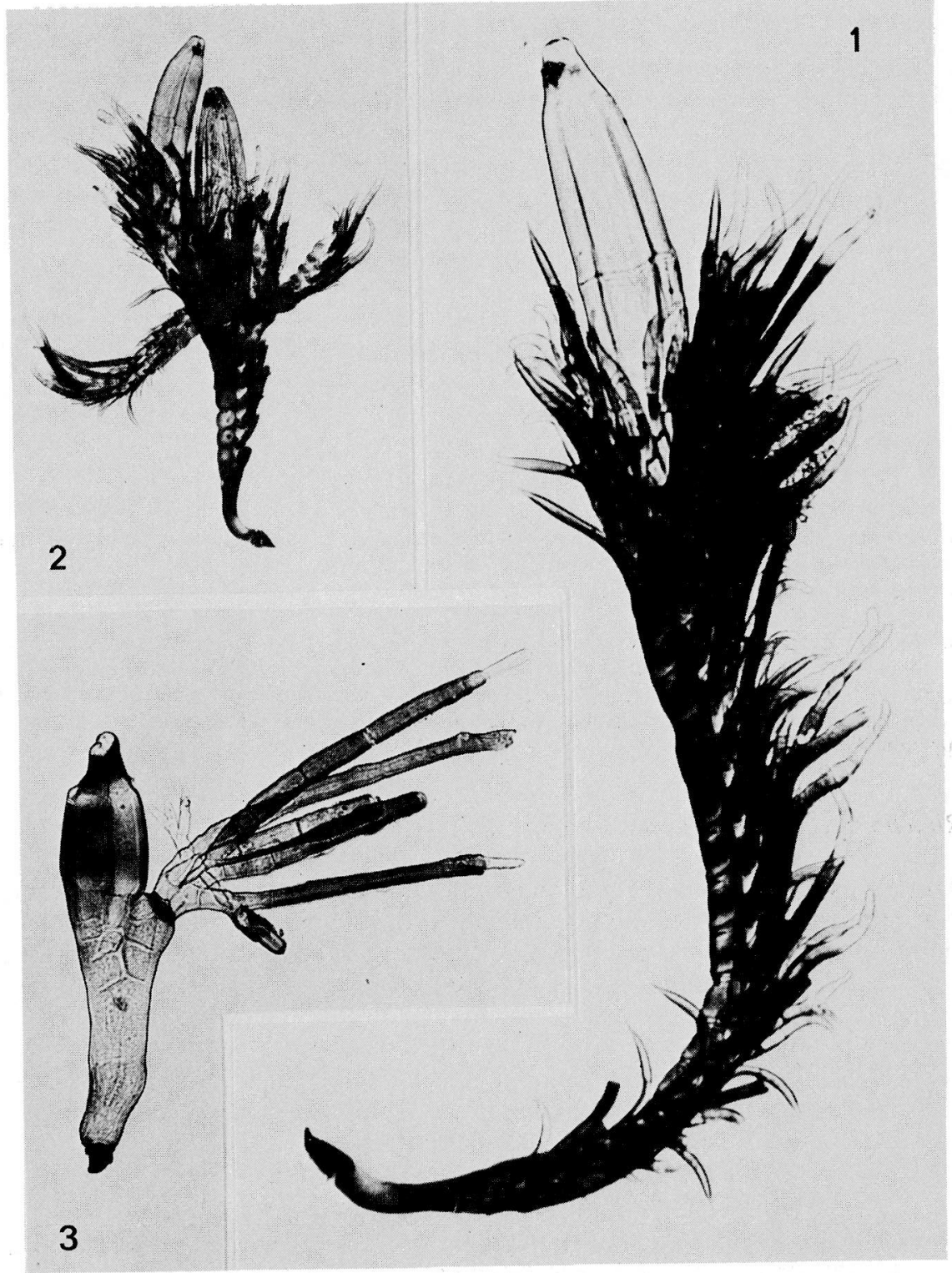

Fig. 1-2. Rhachomyces beronii n. sp. : 1) isotype (x 290); 2) individu anormal, ramifié (x 140). Fig. 3 : Laboulbenia flagellata Peyr. (x 190). 
Antheridia perplura, iuxta totum fungi axem disposita, ad basim perithecii vero frequentiora, pediculo instructa, cinerea ac pellucida, sed progressu aetatis recta et acuta fiunt, Perithecium brevi pediculo instructum, cineraceum ac pellucidum, conspicuis septis, circiter triplo ac dimidio longius quam latius; apicalis pars truncato-conica, paulo fuscior; apex hyalinus ac simus. Trichogynae residuum atrum, valde conspicuum.

Longitudo ab ungue usque ad perithecii apicem: $510-730 \mu$; perithecii corpus: 140-170 x 38-45 $\mu$; maxima longitudo appendicum: $150 \mu$; sporae: $57 \mu$. Parasitus Speagoni mirabilis Moore, in quadam spelunca Novae Guineae inventi. Typus in auctoris museo.

Cellules basale et subbasale allongées: la subbasale est d'une couleur très sombre, comme les cellules qui la suivent immédiatement. Axe principal (= réceptacle secondaire) formé par 20-30 cellules á peu près aussi hautes que larges, d'une couleur très foncée dans la partie centrale mais beaucoup plus claire, parfois presque hyaline, près des septa. Stigmates allongés, bien visibles. Les cellules de l'axe principal, à l'exception des inférieures, portent de brefs axes secondaires formés par des cellules allongées et séparées par des septa très obliques, et dont chacune porte une anthéridie ou un appendice. Le nombre des cellules qui composent les axes secondaires varie selon la position des cellules d'où ils naissent: les axes secondaires situés au milieu de l'axe principal sont formés par quatre cellules, tandis que ceux qui entourent la base du périthèce peuvent en avoir jusqu'à dix, et portent un grand nombre d'anthéridies. Appendices flexueux, formés par 4 ou 5 cellules: les premières sont d'une couleur brune mais non opaque, de 2 à 3 fois plus longues que larges et séparées par des septa noirs et épais; la dernière est très allongée et hyaline dans sa partie distale. Anthéridies très nombreuses, placées tout le long de l'axe du champignon mais surtout autour de la base du périthèce, pédicellées, grises, translucides, avec le col recourbé et l'apex arrondi; en vieillissant elles deviennent droites et aiguës. Périthèce brèvement pédonculé, â peu près trois fois et demie plus haut que large, d'une couleur grise translucide avec des septa très nets; partie apicale en forme de cône tronqué, légèrement nuancé de brun, avec l'apex hyalin et aplati. Cicatrice du trichogyne noire, très évidente.

Longueur totale: $510-730 \mu$; périthèce: $140-170 \times 38-45 \mu$; longueur des appendices, maximum: $150 \mu$; spores: $57 \mu$. Matériel examiné: nombreux exemplaires, dont une vingtaine mûrs, trouvés sur tout le corps d'un Speagonum mirabile Moore (Coleoptera, Carabidae, Anchomenini) recueilli dans la grotte Selminum Tem, Tifalmin, Papouasie -Nouvelle-Guinée. L'insecte nous a été communiqué par le Dr. P. Beron, à qui nous dédions avec plaisir cette espèce nouvelle.

Rhachomyces beronii ne semble avoir aucune affinité avec les autres formes parasites d'Anchomenini, tandis qu'il présente une certaine ressemblance avec $R$. tenuis Thaxt., décrit sur un petit Carabique indéterminé de Java $(1,2)$. A ce propos il faut dire tout de suite que notre Collègue le Dr. J. Balazuc a retrouvé dans les collections du Musée d'Histoire Naturelle de Paris le Carabique en question, que Thaxter avait étiqueté avec le numéro 113: l'insecte a été déterminé comme Trichotichnus javanus (Andrewes) (Harpalini) par P. M. Hammond 
(Britsh Museum). En comparaison de Rhachomyces tenuis, dont les dimensions sont $800-1000 \mu$ et dont l'axe principal est formé par 30-40 cellules, $R$. beronii est plus petit et son axe est formé par un nombre moindre de cellules (généralement 24-25). De plus $R$. tenuis, n'ayant pas de développement d'axes secondaires comme $R$. beronii, ne présente pas l'abondance d'appendices et d'anthéridies si caractéristique de la nouvelle espèce. Les appendices sont nettement différents chez les deux champignons. Enfin, le périthèce de $R$. beronii est plus grand et sa zone préapicale est beaucoup moins pigmentée que chez $R$. tenuis.

Sur le même insecte, parasité par un grand nombre d'exemplaires de la nouvelle espèce, se trouvaient quelques individus, dont un seulement mûr (Fig. 3), que nous attribuons à Laboulbenia flagellata Peyr., espèce très répandue sur les Anchomenini du globe.

Nous remercions notre Collègue le Dr. J. Balazuc de sa précieuse collaboration, le Dr. D. Pfister du Farlow Herbarium de l'envoi du type de Rhachomyces tenuis, le Dr. L. Cajani de la traduction en latin de la diagnose, et MM. L. Zenobi et $\mathrm{R}$. Buffone de leur collaboration pour la planche photographique.

\section{RESUME}

Rhachomyces beronii $\mathrm{n}$. sp. parasite de Speagonum mirabile Moore (Coleoptera, Carabidae, Anchomenini) de la Nouvelle-Guinée est décrite. La nouvelle espèce ressemble à Rhachomyces tenuis Thaxt, par sa forme générale, mais en diffère par un réceptacle plus petit, un périthèce plus grand et moins pigmenté, une structure différente des appendices et par la multiplication des cellules appendiculées. 